\title{
Studies on Some Plant Extracts for Their Antimicrobial Potential against Certain Pathogenic Microorganisms
}

\author{
Muzafar Sheikh $^{1 *}$, Abdul Rashid Malik ${ }^{1}$, M. K. Meghavanshi ${ }^{2}$, Irshad Mahmood $^{1}$ \\ ${ }^{1}$ Plant Pathology Lab, Department of Botany, Aligarh Muslim University, Aligarh, India; ${ }^{2}$ Department of Botany, Bundelkhand Uni- \\ versity, Jhansi, India. \\ Email: "sheikhmuzafar4@gmail.com
}

Received October $22^{\text {nd }}, 2011$; revised December $6^{\text {th }}, 2011$; accepted January $4^{\text {th }}, 2012$

\begin{abstract}
The aim of the present study was to check the antimicrobial potential of eleven different aqueous leaf extracts on Xanthomonas campestris, Agrobacterium rhizogenes and Aspergillus fumigatus based on formation of the zone of inhibition (ZOI). Prosopis juliflora showed maximum and significant inhibitory effect on the growth of all the three pathogens. In case of Xanthomonas campestris the effect of this plant extract was almost equal to the strength of Streptomycin $10 \mathrm{mcg}$, (the metric system uses the term mcg to represent micrograms). Aqueous extracts of some plants formed low zone of inhibition. While some plant extracts were comparatively more effective against all the three pathogens (Xanthomonas campestris, Agrobacterium rhizogenes and Aspergillus fumigatus).
\end{abstract}

Keywords: Zone of Inhibition; Aqueous Leaf Extracts; Antimicrobial Activity

\section{Introduction}

The use of plant compounds to treat infection is an ageold practice in a large part of the world, especially in developing countries, where there is dependence on traditional medicine for a variety of diseases [1]. According to World Health Organization [2] medicinal plants would be the best source to obtain a variety of drugs. In recent years attention has been given to natural systems of treatment for protection and management against pathogens. Plant extracts have played significant role in the inhibition of pathogens and in the improvement of quality and yield of food [3]. A large number of plant species have been investigated for their antimicrobial properties by previous workers, existing antimicrobials are not eco-friendly, and the loss caused by the pathogenic microorganisms is a matter of concern.

The use of plant extracts with known antimicrobial properties can be of great significance in disease treatments.

Xanthomonas campestris is a bacterial species, which causes a variety of plant diseases, infecting all cultivated varieties of brassicas worldwide [4]. Agrobacterium rhizogenes causes an interesting disease called hairy root, due to the abnormal proliferation of numerous roots from the site of infection. Agrobacterium rhizogenes is no doubt a blessing but sometimes it is an evil by distorting

"Corresponding author. the roots of plants and hinders the uptake of water and minerals. Diseases caused by the genus Aspergillus are named aspergillosis. This includes invasion and damage of tissues in an animal that can be widespread and rapidly fatal. For emphasis, aspergillosis is the second most common fungal infection requiring hospitalization [5]. Aspergillus fumigatus is a fungus of the genus Aspergillus, and is one of the most common Aspergillus species to cause disease in individuals with an immunodeficiency disease, it cause diseases mostly in animals.

There is an urgent need to shift towards eco-friendly technologies to reduce the loss. Plants produce hundreds to thousands of diverse chemical compounds with different biological activities. Natural plant extracts have been tested in the laboratory against bacteria and fungi. Plant products yield extracts with antimicrobial activities. At present quick and effective management of plant diseases and microbial contaminations is generally achieved by the use of synthetic pesticides [6-8]. In developing countries such as India they are still being used despite their harmful effects $[9,10]$. Many pathogenic microorganisms and insect pests have developed resistance against these chemical pesticides [11-13]. Considering the deleterious effects of synthetic pesticides on life supporting system there is an urgent need of alternatives for management of pathogenic microorganisms $[14,15]$. Hence, more studies pertaining to the use of plant extracts for controlling the disease should be emphasized. 


\section{Materials and Methods}

\subsection{Plant Material}

Fresh leaves of eleven different plant species free from diseases were collected. The leaves were washed thoroughly 2 to 3 times with running tap water, leaf material was then air dried under shade. After complete shade drying the plant material was grinded in the mixer, the powder was kept in small plastic bags with proper labeling. For aqueous extract preparation $5 \mathrm{~g}$ of plant material were crushed in $25 \mathrm{ml}$ of distilled water and it was filtered using what man filter paper No. 1. The filtrate was collected in sterile bottles and was stored in refrigerator at $5^{\circ} \mathrm{C}$ until use [16].

\subsection{Bacterial Culture}

Authentic pure cultures of Phytopathogenic Xanthomonas campestris and Agrobacterium rhizogenes were obtained from Microbial Type Culture Collection Centre [MTCC] Institute of Microbial Technology [IMTECH] Chandigarh in lyophilized vial.

\subsection{Fungi Culture}

The culture of fungi was obtained from the Department of Biomedical science, A. M. U. Aligarh, the culture was maintained on the SDA medium using standard protocols.

\subsection{Preliminary Screening for Antibacterial Activity}

The preliminary screening was done by well in agar method i.e. the bacterial cultures were spread on the agar surface using sterile cotton swab, then a well of $5 \mathrm{~mm}$ was made in the agar medium using sterile cork borer, 85 $\mathrm{ml}$ of aqueous extract were transferred into separate wells and plates were incubated at $27^{\circ} \mathrm{C}$ for 24 hours, three replicates were produced for each extracts [17].

\subsection{Antifungal Activity Assay}

The antifungal testing was carried using well in Agar method. SDA was poured into Petri dishes and allowed to solidify, then a well of $5 \mathrm{~mm}$ was made in the medium using sterile cork borer, $85 \mathrm{ml}$ of aqueous extract were transferred into separate wells and plates were incubated at $28^{\circ} \mathrm{C}$ to $31^{\circ} \mathrm{C}$ for 48 hours. Zone of inhibition was measured after 48 hours .Three replicates were produced for each extract.

\section{Results}

Data on Antimicrobial activity measure as a zone of inhibition of aqueous extracts of eleven plant species and two antibiotics on Agrobacterium rhizogenes, Xanthomonas campestris and Aspergillus fumigatus have been shown in Tables 1-3 and represented by the Figures 1-3 respectively.

Table 1. Zone of inhibition (mm) of aqueous extracts of eleven plant species and two antibiotics on Agrobacterium rhizogenes.

\begin{tabular}{cccc}
\hline S. No & Name of plant & Part used & ZOI $(\mathrm{mm})^{*}$ \\
\hline 1 & Ageratum conyzoides & Leaves & 0.00 \\
2 & Boerhaavia diffusa & Leaves & 0.00 \\
3 & Dathura stramonium & Leaves & 0.00 \\
4 & Euphorbia hirta & Leaves & $7.5 \pm 0.166^{\mathrm{a}}$ \\
5 & Hyptis suaveolens & Leaves & $6.5 \pm 0.166^{\mathrm{b}}$ \\
6 & Jatropha gossypifolia & Leaves & 0.00 \\
7 & Phyllanthus niruri & Leaves & 0.00 \\
8 & Prosopis juliflora & Leaves & $15.66 \pm 1.22^{\mathrm{a}}$ \\
9 & Solanum nigrum & Leaves & 0.00 \\
10 & Tridex procumbens & Leaves & 0.00 \\
11 & Ziziphus jujube & Leaves & 0.00 \\
12 & Streptomycin & (10 mcg) & $18.66 \pm 1.22^{\mathrm{b}}$ \\
13 & Tetracycline & (13 mcg) & $5.33 \pm 0.55^{\mathrm{a}}$ \\
\hline
\end{tabular}

${ }^{*}$ Values are mean of three replicates \pm Standard error Values without common letters are significantly different at LSD P $=0.05$.

Table 2. Zone of inhibition ( $\mathrm{mm}$ ) of aqueous extracts of eleven plant species and two antibiotics on Xanthomonas campestris.

\begin{tabular}{cccc}
\hline S. No & Name of plant & Part used & ZOI (mm) \\
\hline 1 & Ageratum conyzoides & leaves & $7.00 \pm 0.57^{\mathrm{a}}$ \\
2 & Boerhaavia diffusa & leaves & 0.00 \\
3 & Dathura stramonium & leaves & 0.00 \\
4 & Euphorbia hirta & leaves & $6.5 \pm 0.49^{\mathrm{b}}$ \\
5 & Hyptis suaveolens & leaves & 0.00 \\
6 & Jatropha gossypifolia & leaves & 0.00 \\
7 & Phyllanthus niruri & leaves & $7.50 \pm 0.57^{\mathrm{b}}$ \\
8 & Prosopis juliflora & leaves & $14.33 \pm 0.33^{\mathrm{b}}$ \\
9 & Solanum nigrum & leaves & 0.00 \\
10 & Tridex procumbens & leaves & 0.00 \\
11 & Ziziphus jujube & leaves & 0.00 \\
12 & Streptomycin & $(10 \mathrm{mcg})$ & $16.33 \pm 1.21^{\mathrm{a}}$ \\
13 & Tetracycline & $(13 \mathrm{mcg})$ & $4.50 \pm 0.50^{\mathrm{b}}$ \\
\hline
\end{tabular}

*Values are mean of three replicates \pm Standard error Values without common letters are significantly different at LSD P $=0.05$. 
Table 3. Zone inhibition (mm) of aqueous extracts of eleven plant species and two antibiotics on Aspergillus fumigatus.

\begin{tabular}{cccc}
\hline S. No & Name of plant & Part used & ZOI (mm $)^{*}$ \\
\hline 1 & Ageratum conyzoides & leaves & $8.33 \pm 0.33^{\mathrm{a}}$ \\
2 & Boerhaavia diffusa & leaves & 0.00 \\
3 & Dathura stramonium & leaves & 0.00 \\
4 & Euphorbia hirta & leaves & 0.00 \\
5 & Hyptis suaveolens & leaves & $5.66 \pm 0.57^{\mathrm{b}}$ \\
6 & Jatropha gossypifolia & leaves & $6.33 \pm 0.72^{\mathrm{a}}$ \\
7 & Phyllanthus niruri & leaves & 0.00 \\
8 & Prosopis juliflora & leaves & $11.00 \pm \mathrm{s} 0.57^{\mathrm{b}}$ \\
9 & Solanum nigrum & leaves & 0.00 \\
10 & Tridex procumbens & leaves & 0.00 \\
11 & Ziziphus jujube & leaves & 0.00 \\
12 & Streptomycin & (10 mcg) & 0.00 \\
13 & Tetracycline & (13 mcg) & 0.00 \\
\hline
\end{tabular}

*Values are mean of three replicates \pm Standard error Values without common letters are significantly different at LSD P $=0.05$.

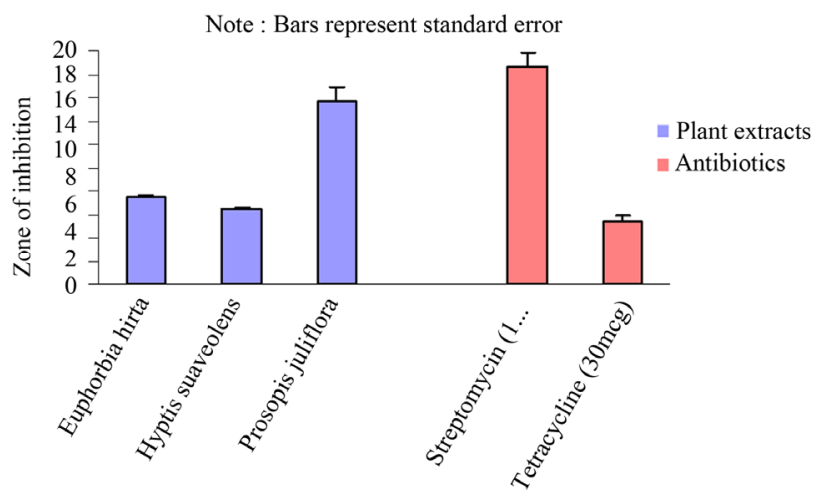

Figure 1. Zone of Inhibition (mm) of Aqueous extracts of some plant species and to antibiotics on Agrobacterium rhizongenes.

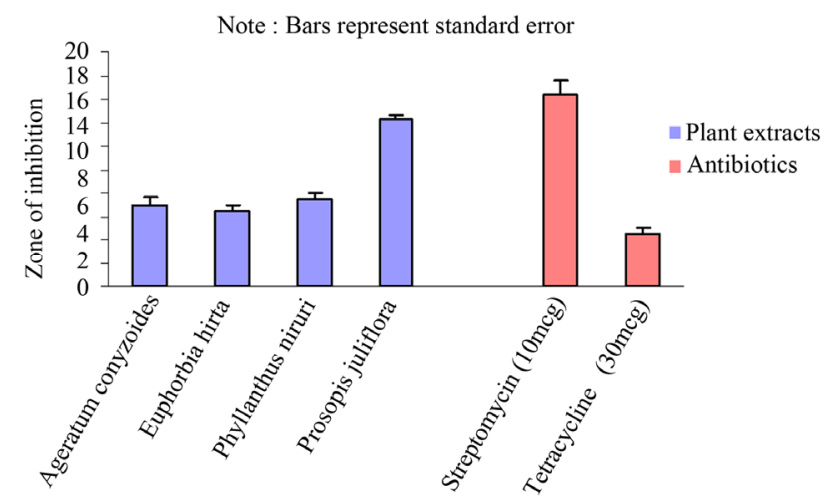

Figure 2. Zone of Inhibition (mm) of Aqueous extracts of some plant species and to antibiotics on Xanthomonas campestris.

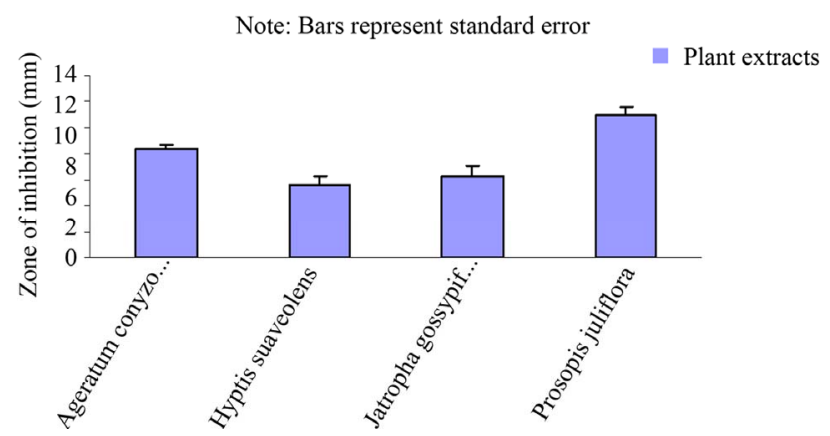

Figure 3. Zone of Inhibition (mm) of Aqueous extracts of some plant species.

As is evident from Table 1 leaf extracts of Prosopis juliflora, Euphorbia hirta, and Hyptis suaveloens formed $15.66 \pm 1.22 \mathrm{~mm}, 7.5 \pm 0.166 \mathrm{~mm}$ and $6.5 \pm 0.166 \mathrm{~mm}$ zone of inhibition (ZOI) around the well in nutrient agar Petri dishes. Aqueous extract of leaves of other plants shown in the Table 1 did not form any zone. Contrary to this extract from Prosopis juliflora leaves showed maximum ZOI i.e. $19.66 \pm 1.81 \mathrm{~mm}$. Furthermore ZOI formed around the antibiotic discs streptomycin $(10 \mathrm{mcg})$ and Tetracycline $(30 \mathrm{mcg}$ ) were $18.66 \pm 1.22 \mathrm{~mm}$ and $5.33 \pm 0.50 \mathrm{~mm}$ respectively.

Data was analyzed statistically by using SPSS version 16 (Chicago, USA). Means were compared at 5\% level of probability; the data revealed that ZOI formed around the extract of Prosopis juliflora leaves was significantly higher (Plates 1 and 2) than the other extracts. Furthermore it was very much comparable to the zones of inhibition formed around the antibiotic disc of streptomycin $(10 \mathrm{mcg})$. It is evident from Table 2 that leaf extracts of Ageratum conyzoides, Euphorbia hirta, Phyllanthus niruri and Prosopis juliflora formed $7 \pm 0.57 \mathrm{~mm}, 6.5 \pm$ $0.57 \mathrm{~mm} .14 .33 \pm 0.33 \mathrm{~mm}$ zone of inhibition around the well in the nutrient agar Petri dishes. The other plants listed in the Table 2 did not form any zone of inhibition. From the above it is evident that Ageratum conyzoides and Phyllanthus niruri formed zone of inhibition around the well. However in case of Agrobacterium rhizogenes these two plants did not formed any zone. Furthermore, ZOI formed around the the antibiotic discs Streptomycin $(10 \mathrm{mcg})$ and Tetracycline $(30 \mathrm{mcg})$ were $16.3 \pm 1.21$ $\mathrm{mm}$ and $5.33 \pm 0.50 \mathrm{~mm}$ respectively. Prosopis juliflora aqueous leaf extracts were showing significant inhibitory activity on all the three pathogens the other leaf extracts. the Data pertaining to antifungal activity of aqueous extracts of eleven plant species and two antibiotics on Aspergillus fumigatus revealed that leaf extracts of Ageratum conyzoides, Hyptis suavolens, Jatropha gossypifolia and Prosopis juliflora formed $8.33 \pm 0.33 \mathrm{~mm}, 5.6 \pm 0.57$ mm, $6.33 \pm 0.72 \mathrm{~mm}$ and $11 \pm 0.57 \mathrm{~mm}$ Extracts of Prosopis juliflora leaves formed maximum ZOI $(11 \pm 0.57$ $\mathrm{mm}$ ) amongst all the listed extracts. Aqueous extracts 


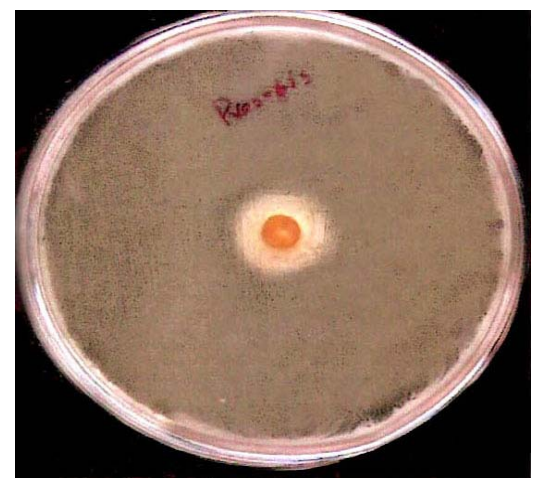

Plate 1. Antifungal activity of Prosopis juliflora leaf extract.

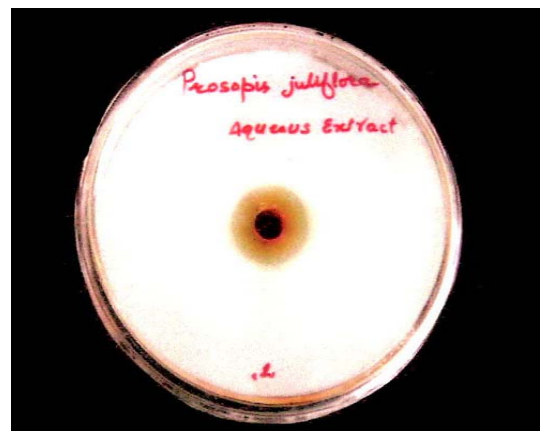

Plate 2. Antibacterial activity of Prosopis juliflora leaf extract.

from rest of the plant samples did not show any zone. Similarly, no ZOI was observed around the antibiotic discs streptomycin $(10 \mathrm{mcg})$ and tetracycline $(30 \mathrm{mcg})$.

\section{Discussion}

According to Baur [18], the activity is resistant if the ZOI is less than $8.00 \mathrm{~mm}$, intermediate if greater than 11.00 $\mathrm{mm}$. Comparing this Xanthomonas campestris, Agrobacterium rhizogenes, and Aspergillus fumigatus could be regarded as sensitive to aqueous extract of Prosopis juliflora. The aqueous extracts of some plants did not form any ZOI; this could be due to compounds of other class un dissolved in water. Aqueous extract of Hyptis suaveolens formed low ZOI probably due to compounds of class partially dissolved in water. Other test plant extracts that did not form inhibitory zones may not contain the water dissolving active antimicrobial compounds or contain it in other complex forms un dissolved in water. Statistical analysis (ANOVA followed by LSD P $=0.05$ ) of the data on antifungal activity of aqueous extract of eleven plant species and two antibiotics on Aspergillus fumigatus indicate that ZOI formed around aqueous extract of Prosopis juliflora and Ageratum conyzoides leaves were significantly high in comparison to that of Hyptis suaveolens and Jatropha gossypifolia. In the present study the evaluation of antimicrobial activity of aqueous plant extracts was based on formation of zone of inhibition around the $5 \mathrm{~mm}$ well on the Petri dishes filled with nutrient media and smeared with test pathogens. In general data on antimicrobial activity of eleven plant species and two antibiotics on Xanthomonas campestris, Agrobacterium rhizogenes, and Aspergillus fumigatus. Prosopis juliflora showed maximum and significant inhibitory effect on the growth of all the three pathogens. Furthermore in case of Xanthomonas campestris the effect of this plant extract was almost equal to the strength of Streptomycin (10 mcg).

No doubt this piece of work seems to be ordinary, but in real sense this study can help us in achieving the target aim to reduce or to eradicate the target pathogens in an eco-friendly way, furthermore the leaf extracts were obtained from mostly weeds, weeds are unwanted plants or plants out of place, so we have tried to obtain the target aim by mixing the plant extracts in water, that too is not a costly approach and the results are satisfactory.

\section{Acknowledgements}

The Authors are thankful to chairman Department of Botany, Aligarh Muslim University, Aligarh for providing necessary research facilities.

\section{REFERENCES}

[1] J. Gangoue-pieboji, D. E. Pegnyemb and D. Niyitegeka, "The in-Vitro Antimicrobial Activities of Some Medicinal Plants from Cameroon,” Annals of Tropical Medicine and Parasitology, Vol. 100, No. 3, 2006, pp. 273243. doi:10.1179/136485906X86365

[2] P. R. V. Santo, A. C. X. Oliveira and T. C. B. Tomassini, "Controle Microbiogico de Produtos Filoterapicos," Revista de Farmacia e Bioquimica, Vol. 31, 1990, pp. 3538.

[3] E. O. Nwachukwe and C. I. Umechurma, "Antifungal Activities of Some Leaf Extracts and Seed Borne Fungi of African Yam Bean Seeds, Seed Germination and Seedling Emergence," Journal of Applied Science and Environmental Management, Vol. 5. No. 1, 2001, pp. 29-32.

[4] A .M. Alvarez, A. J. Slusarenko, R. S. S. Fraser and L. C. Van Loon, "Mechanisms of Resistance to Plant Diseases," Kluwer Academic Publishers, Dordrecht, 2000, pp. 21-52. doi:10.1007/978-94-011-3937-3_2

[5] J. E. Smith, “Aspergillus Biotechnology Handbooks Series,” Plenum Press, New York, 1994.

[6] Anon, "Pesticide Incidents up for Compared with Previous Year,” International Pest Control, Vol. 40, 1998, pp. 1-8.

[7] R. J. Williams and D. L. Heymann, "Containment of Antibiotic Resistance,” Science, Vol. 279, No. 5354, 1998, pp. 1153-1154. doi:10.1126/science.279.5354.1153

[8] G. N. Agrios, "Control of Plant Diseases. In Plant Pathology," 4th Edition, Academic Press, London, 1997, pp. 200-216.

[9] Anon, "Pharmacopoeia of India, the Indian Pharmaco- 
poeia," 3rd Edition, Ministry of Health and Family Welfare, Government of India, New Delhi, 1996.

[10] A. Wodagench and H. V. D. Wulp, "Obsolete Pesticides in Developing Countries," Pesticides Information, Vol. 23, 1997, pp. 33-36.

[11] P. A. Urech, T. Staub and G. Voss, "Resistance as a Concomitant of Modern Crop Protection,” Pesticides Science, Vol. 51, No. 3, 1997, pp. 227-234. doi:10.1002/(SICI)1096-9063(199711)51:3<227::AID-PS 646>3.0.CO;2-X

[12] R. J. Sbragia, "Chemical Control of Plant Diseases an Exciting Future," Annual Review of Phytopathology, Vol. 13, 1975, pp. 257-269. doi:10.1146/annurev.py.13.090175.001353

[13] W. Witte, "Medical Consequences of Antibiotic Use in Agriculture,” Science, Vol. 279, No. 5353, 1998, pp. 996997. doi:10.1126/science.279.5353.996
[14] H. A. Bolkan and W. R. Reinert, "Developing and Implementing IPM Strategies to Assist Farmers: An Industry Approach,” Plant Diseases, Vol. 78, No. 6, 1994, pp. 545-550. doi:10.1094/PD-78-0545

[15] M. J. Rice, M. Leg and K. A. Powell, "Natural Products in Agriculture-A View from Industry," Pesticides Science, Vol. 52, No. 2, 1998, pp. 184-188. doi:10.1002/(SICI)1096-9063(199802)52:2<184::AID-PS 681>3.0.CO;2-P

[16] S. P. Gupta, "Statistical Methods," Sultan Chand and Sons, New Delhi, 2000.

[17] D. O. Dhigra and B. James, "Basic Plant Pathology Methods,” CRC Press, London, Vol. 1, 1995, pp. 287-305.

[18] A. W. Baur, W. M. Kirby, J. S. Sherris and M. Turck, "Antibiotic Susceptibility Testing by a Standard Single Disk Method," American Journal of Clinical Pathology, Vol. 45, 1996, pp. 493-496. 